\title{
DUAS REVISTAS, TRÊS ARTIGOS, MÚLTIPLAS VOZES: UM ESTUDO SOBRE MODOS DE DIZER E POSIÇÓES SOCIAIS EM TEXTOS PARA PROFESSORES*
}

\author{
Ana Luiza Bustamante Smolka ${ }^{* *}$ \\ MÔNica SALles Gentil ${ }^{* * *}$
}

\begin{abstract}
RESUMO: Neste texto, apresentamos um estudo analítico comparativo de duas revistas da área da educação, destinadas a professores. Colocamos em foco, mais especificamente, dois números que tiveram como reportagem de capa o tema da violência e destacamos para análise três textos nelas publicados. Buscamos colocar em evidência algumas condiçōes de produção que caracterizam as revistas e os textos o contexto histórico-social, o suporte material, as posições e as imagens dos interlocutores (autores, leitores, professores, editores, repórteres) -, discutindo como essas condiçōes são constitutivas da autoria e dos modos de apresentação da temática.
\end{abstract}

Palavras-chave: Revistas de educação. Produção de textos. Posições sociais.

TWO JOURNALS, THREE PAPERS, MULTIPLE VOICES:

A STUDY ON THE WAYS OF SAYING AND SOCIAL POSITIONS IN TEXTS

FOR TEACHERS

ABSTRACT: This text presents an analytical comparative study of two journals published for teachers in Elementary Education. It focuses more specifically on two issues whose cover matter was violence, through three selected texts related to this problem. Through these analyzes, it attempts to turn visible some conditions of production that characterize both the journals and the texts - the historical

* Queremos agradecer o incentivo e as sugestôes de Adriana L. F. Laplane e Ana Lúcia H. Nogueira na elaboração deste texto.

** Doutora em Educação pela Universidade Estadual de Campinas (UniCAmp) e professora do Programa de Pós-Graduação em Educação na mesma Instituição. E-mail: asmolka@unicamp.br

*** Doutoranda em Educação pela unicAmp.E-mail: mogentil@uol.com.br

Cad. Cedes, Campinas, vol. 24, n. 63, p. 193-213, maio/ago. 2004

Disponível em <http://www.cedes.unicamp.br> 
Duas revistas, três artigos, múltiplas vozes...

social context, the material support, the positions and images of interlocutors - and discusses how such conditions of production are constitutive of authorship as well as of the modes of thematic presentation.

Key words: Education journals. Text production. Social positions.

\section{Introdução}

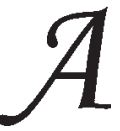

relação dos professores com o conhecimento tem sido uma questão amplamente debatida em diferentes fóruns e instâncias - nas escolas, na mídia, na academia - e tem levado em conta diferentes aspectos - a formação que esse profissional recebe ou deixa de receber, as informaçóes às quais tem ou não acesso, o conhecimento que ele possivelmente constrói, o que ele deve ou não ensinar, o que sabe ensinar, para quem ensina etc.

Repercutindo fortemente na e por intermédio da mídia, estas discussōes acabam por contribuir tanto na formação de professores quanto na formação de opiniōes sobre o que é ser professor. Desse modo, as formas de atuação dos professores, bem como as opinióes que vão sendo trabalhadas nessas variadas instâncias, vão compondo e constituindo as múltiplas imagens da função social desse profissional da educação.

Uma das questões que emerge nessas discussões é a de como ele desempenha essa função, que subsídios sustentam sua prática. De que recursos, por exemplo, ele lança mão para a realização de sua atividade profissional, hoje? Como ele lida com a demanda de atualização constante do conhecimento? Podemos apontar os inúmeros cursos, palestras, encontros, oferecidos pelas Diretorias e Secretarias de Educação; os diversos programas e planos oficiais; as leis e os Parâmetros Curriculares Nacionais (PCNs); ainda, os manuais e o material de leitura disponíveis ou acessíveis nas bibliotecas, nas escolas. Entre esses recursos e materiais, uma das referências constantes dos professores têm sido as revistas de ampla divulgação, inclusive disponíveis em bancas de jornais.

A partir dessas referências, começamos a levantar várias indagações sobre as relações dos professores com esse tipo de produção cultural e com o conhecimento nele veiculado. Que leituras se tornam 
viáveis no cotidiano da prática profissional dos professores? Que condições de leitura os professores, em geral, têm? Que materiais lhes são mais acessíveis e atendem a suas expectativas, desejos, necessidades? $\mathrm{O}$ que os motiva na busca desses materiais? $\mathrm{O}$ que eles encontram em resposta às suas buscas?

Nosso trabalho se insere, assim, no âmbito das discussões que vêm sendo promovidas por vários especialistas na área, os quais têm destacado como objeto de estudo as revistas destinadas a professores. Neste texto, vamos enfocar duas revistas da área da educação, citadas por professores, e que já foram objeto de análises diferenciadas em, pelo menos, uma dissertação de mestrado e uma tese de doutorado da UfMG: Nova Escola (NE), analisada por Marta Vieira, em 1995; e Presença Pedagógica (PP), uma das três revistas mineiras analisadas por Isabel Frade, em 2000, respectivamente. Vieira analisa na NE o conceito de construtivismo e suas formas de apresentação. Frade faz um estudo comparativo das três revistas, entre elas a PP, destacando as características do suporte, dos modos de produção, da construção da autoria e a relação da editora com seu público.

Dessas revistas, vamos destacar três textos, cujo estudo inicial teve como ponto de partida uma apresentação na ABRAPSO, ${ }^{1}$ integrando um simpósio em que os trabalhos apresentados estavam relacionados à violência, à emoção e à escolarização. Vinculado ao projeto de pesquisa então em andamento, que incluía uma análise de revistas destinadas a professores, colocou-se como um objetivo específico examinar alguns textos relacionados à temática. Selecionamos três artigos publicados no ano de 1999, nas duas revistas mencionadas: "Escola e comunidade: resistência à violência" e "A humanização do ensino no combate à violência", na PP do bimestre julho/agosto; e "O desarme da violência", na NE do mês de setembro. Optamos por realizar um estudo analítico comparativo das revistas e dos textos.

Em nossas análises, buscaremos dar visibilidade a possíveis relaçôes entre os modos de dizer - apresentar, problematizar, argumentar - e os lugares sociais, institucionais, ocupados pelos produtores autores, editores - dos textos de divulgação. Buscaremos analisar e colocar em evidência algumas condições de produção que caracterizam as revistas - o contexto histórico-social, os interlocutores, o lugar de onde falam -, discutindo os modos como essas condições constituem os modos de apresentação da temática. 
Duas revistas, três artigos, múltiplas vozes...

\section{As revistas}

Uma análise de vários números das revistas mostra-nos que as duas se apresentam em cores, incluem imagens, mas fazem-no de maneiras diferenciadas. A NE apresenta os textos em letra com corpo $10 \mathrm{e}$ espaçamento simples nas entrelinhas, o que torna a configuração visual da matéria impressa densa e compacta. A revista traz um grande número de fotos de pessoas, protagonistas e autores dos textos, bem como fotos de locais ou situações escolares. Isso aponta para uma função que vai além da ilustração: as fotos entram na composição do texto escrito, produzindo, com isso, um efeito de evidência. Esse efeito emerge da relação entre essa forma de ilustração e o tipo de texto que caracteriza a revista: a reportagem. Ou seja, dado que na reportagem, como discurso jornalístico, privilegia-se a objetividade, a fotografia tende a exibir o fato e a comprovar a existência da pessoa que fala, que escreve, que depõe. Em algumas matérias, geralmente relacionadas à literatura infantojuvenil, encontramos também desenhos ilustrativos.

A pP abre os seus textos com reproduções de obras artísticas, buscando relacioná-las ao tema em questão, e trazendo-as, inclusive, em suas capas. O corpo da letra (11) e o espaçamento nas entrelinhas $(1,5)$ dão à matéria impressa uma configuração bem menos compacta e mais leve em termos de quantidade de texto, se a comparamos com a NE. A PP tem como um dos procedimentos gráfico-editoriais apresentar recortes ou detalhes da reprodução da obra na composição do texto. Esse modo de composição do texto, que entrelaça escrita e recortes de pinturas, sugere a articulação de temáticas e práticas sociais, pontuando diferentes tempos e eventos, dando visibilidade a imbricações entre arte, educação, cultura, história. Também pudemos notar que fotos - de pessoas ou situações - ilustram duas seções, na maioria das vezes: reportagem e entrevista.

A NE foi criada em setembro de 1985 e é editada pela Fundação Victor Civita, entidade sem fins lucrativos mantida pelo Grupo Abril. Sua periodicidade é mensal, sendo que três números, coincidentes com os períodos de férias escolares, contemplam dois meses (janeiro/fevereiro, junho/julho e novembro/dezembro). A média de páginas, no ano de 2003, foi de 66. A NE pode ser encontrada em bancas de jornais pelo preço de $\mathrm{R} \$ 2,00$. O valor da assinatura anual da NE é de R\$20,26. 
A PP teve origem em 1995 e tem sido editada bimestralmente, pela editora Dimensão, em Minas Gerais. Teve como editor em seu primeiro ano de existência um professor que, na época, era diretor da Faculdade de Educação da Universidade Federal de Minas Gerais (UFMG). Durante vários anos, o número de páginas em cada número foi variável (de 86 a 116). Em 2003, todos os números passaram a ter 80 páginas. A PP é acessível somente por assinatura, sendo o preço de capa $\mathrm{R} \$ 16,00$. O valor da assinatura anual da pp é de $\mathrm{R} \$ 86,00$.

As duas revistas apresentam propagandas de tipos diferentes: na $\mathrm{PP}$, encontramos algumas poucas propagandas de produtos da editora que a edita; na NE, várias propagandas relacionadas à área da educação, como, por exemplo, de colégios, livros e materiais didáticos, sistemas de ensino. Isso indica formas também diferenciadas de sustentação e condições de produção das revistas. Segundo Frade,

a inclusão da publicidade no impresso sofreu mudanças, na história do livro e da imprensa. (...) A publicidade não é mais uma estratégia à parte e pode-se dizer que, além do fato de ela sustentar hoje muitos projetos editoriais, convive, de forma cada vez mais agressiva, com o restante das informações existentes nos impressos, produzindo alteraçôes nos modelos de produção textual e gráfica, na estética e, sobretudo, na leitura. (2000, p. 96)

Ou seja, ter ou não o apoio de uma fundação, ser vendida ou não a preço de custo, incorporar ou não material publicitário (tipo e quantidade) faz diferença. Essa diferença também se explicita nos modos de organização das revistas e nos próprios objetivos formulados.

Quanto às formas de organização, divisão e escolha de seções nas revistas, é interessante observar as nuances nos modos de nomeação e apresentação de cada uma delas, e buscar compreender como uma mesma designação marca funções diferenciadas.

De acordo com a Ficha Técnica da revista NE, os Colaboradores têm como atribuição cuidar do tratamento de imagens e da revisão, função exercida por um período de tempo variável, não restrito a cada número. A Ficha Técnica da NE traz ainda a identificação com relação a Editores, sendo que seus nomes ou suas iniciais constam também nos textos, juntamente ou não com os de repórteres, indicando a autoria. $\mathrm{Na}$ Pp, Colaboradores são os autores dos textos, e mudam a cada nú- 
Duas revistas, três artigos, múltiplas vozes...

mero. Esses colaboradores têm suas qualificações especificadas em nota de rodapé no início do texto publicado. Vale ressaltar que, ao final da Ficha Técnica da Pp, lê-se a seguinte chamada: "Aceitam-se colaborações", o que indica nessa revista um convite à participação como autor. $\mathrm{Na}$ PP encontramos uma editora-geral e uma assistente, sendo esta última a única da Ficha Técnica identificada como jornalista.

No que se refere à organização e à nomeação das seções, é interessante notar como o termo Reportagem é usado em cada uma das revistas: na NE, Reportagens e seçōes aparece como uma categoria que abarca um conjunto de reportagens e artigos, distinguindo-o de um outro conjunto caracterizado como Caderno de Atividades. ${ }^{2} \mathrm{Na} \mathrm{PP}, R e-$ portagem é o nome dado a uma seção específica, que não consta em todos os números, e tem autoria definida e variada.

No que diz respeito aos objetivos formulados, encontramos em destaque na NE: "Nova Escola é vendida a preço de custo. Você só paga o papel, a impressão e a distribuição, porque a Fundação Victor Civita, criada em setembro de 1985, tem como objetivo contribuir para a melhoria da qualidade do Ensino Fundamental, por meio da qualificação e do apoio ao professor brasileiro". ${ }^{3}$ De acordo com o "idealizador" da revista, que dá nome à Fundação, "Não temos a pretensão de salvar a Educação brasileira. Mas entendemos que uma professora bem informada tem maiores chances de desempenhar melhor suas tarefas em sala de aula do que outra que não receba nenhuma ou quase nenhuma informação" (apud Vieira, 1995, p. 23).

Destacamos também um trecho de um documento de circulação interna da NE, escrito em 1992, pelo redator-chefe: "Trata-se ainda de uma publicação de caráter estritamente jornalístico - e não pedagógico - editada e escrita por jornalistas, para ser lida por educadores. O que significa que, em suas reportagens, entrevistas e notas, a fala ou o pensamento dos educadores ouvidos pelos repórteres e editores aparecerão sempre editados segundo critérios jornalísticos, tais como a hierarquização dentro de um assunto, a pluralidade de opiniōes" (idem, ibid., p. 23-24).

Segundo depoimento de Graça Paulino, atual editora da PP, a revista surge como "uma proposta de intervenção no panorama geral das publicações para professores da época, que seria assim uma pro- 
posta de renovação, com a interferência da universidade, de alguns especialistas da universidade, de alguns acadêmicos que estavam ligados ao trabalho de formação de professores, ao trabalho no ensino básico" (apud Frade, 2000, p. 74). E ela comenta ainda: "Eu acho que é uma revista que tem interessado mais ao pessoal da Pedagogia, da Educação, mas é uma revista para professores também, na medida em que nós nunca deixamos de pensar a educação matemática, a educação de ciências (...)” (idem, ibid., p. 244).

Encontramos, portanto, na NE, os objetivos explícitos da informação e da acessibilidade a todas - note-se aqui o uso do feminino: (...) uma professora bem informada tem maiores chances de desempenhar melhor suas tarefas (...); e note-se também o argumento da viabilidade do acesso pelo preço de custo: (...). Você só paga o papel, a impressão $e$ a distribuição (...) (e aqui podemos supor que fica fora desse custo o trabalho de editores e autores, sustentado pela Fundação).

$\mathrm{Na}$ Pp, o objetivo explicita a intenção de uma publicação de qualidade diferente da de outras no mercado, e a ênfase é posta na formação, seja do ainda estudante de pedagogia, a quem a revista tem interessado mais, seja do professor em atuação: é uma revista para professores também.

Convém situar esses objetivos, lembrando que a emergência da $\mathrm{NE}$ se insere num movimento mais abrangente de ramificação e especificação do jornalismo - jornalismo científico, econômico, esportivo etc. - ao longo do século XX. O ano de seu surgimento coincide com um dos períodos de maior expansão das concepções do construtivismo no Brasil; momento em que ainda prevalecia a exigência da formação do professor do ensino fundamental apenas no nível do ensino médio. Ao lado de iniciativas do Ministério da Educação, das Secretarias de Educação e das universidades, na divulgação do conhecimento para os professores, a mídia impressa começa a se impor como uma via e um espaço legítimo dessa divulgação. A NE, então, encontra condições favoráveis para seu surgimento e estabelecimento, como um produto no mercado, e com uma função social declarada e explicitada, como podemos perceber nos objetivos anteriormente mencionados.

A PP aparece no cenário editorial em 1995, dez anos depois da NE, um ano antes da publicação da Nova LDB, quando acirradas dis- 
Duas revistas, três artigos, múltiplas vozes...

cussões sobre o nível de formação de professores da educação básica eram freqüentes. Surge no meio acadêmico, com o propósito de distinguir-se e interferir nesse cenário. Traz embutido o objetivo da crítica, a intenção de marcar uma diferença nos modos de divulgação do conhecimento pela mídia, de dentro da própria mídia.

Assim, hoje, quase 20 anos depois do surgimento da NE e 10 após o surgimento da PP, as duas revistas circulam no mercado, atendendo a algumas demandas (por exemplo, informação, divulgação do conhecimento), criando outras, respondendo a interesses e necessidades diversos.

As condições de surgimento das revistas podem ser vistas como intrinsecamente relacionadas às propostas de editoração, às falas/textos de autores e editores, bem como às imagens e posiçôes (de legitimidade, de autoridade) que eles ocupam. Um exame das duas revistas, levando em conta seus formatos e suportes materiais (publicações periódicas), a área prioritária de circulação (educação), o público a que se destina (professores), mostra-nos que numa aparente similaridade encontramos distinções relevantes. Se um preço mais elevado e a forma de compra por assinatura podem ser considerados fatores que tornam a circulação mais restrita, é importante considerar como essas condições de acessibilidade se encontram relacionadas aos objetivos diferenciados, às possibilidades e aos projetos editoriais distintos. Esses aspectos, que aparecem como constitutivos das revistas, incluem as imagens dos possíveis leitores criadas pelos editores/autores de cada revista, sendo também definidores do público leitor.

Tais imagens não são construídas de um modo simples, por um decreto ("Queremos público leitor que tenha as seguintes características...") ou uma mera definição ("O leitor ideal para nossa revista é aquele que..."). Assim, por exemplo, "podemos imaginar o nosso leitor - professor é também pensado, imaginado pelos outros profissionais (o editor, o ilustrador, o revisor) - que, ao lado do autor, fabrica a obra, seja ela o impresso que for. Portanto, as imagens (...) estão inscritas nos impressos, pelo trabalho de muitas mãos, que ora agem em sintonia de intenções e de opiniōes, ora não. Elas se manifestam na conjunção dos diferentes aspectos da produção cultural destinada aos professores: tipo de papel, de letra, de impressão, formato, diagramação, ilustração, seleção/conteúdo dos textos, comentários, notas etc.” (Silva, 1998, p. 143). 
Esse movimento de (inter)constituição de autores, leitores, editores, professores nos leva a uma discussão mais detida dos lugares e das posições sociais relacionados aos modos de realização do trabalho de autoria. Ante as rápidas e intensas transformaçôes tecnológicas, que vêm provocando profundas mudanças nas formas de produção, acesso e divulgação do conhecimento - particularmente via internet -, novas e prementes questôes sobre as formas de autoria e de leitura, sobre os modos de composição de textos etc. têm se colocado: cópia, plágio, pastiche, copyright, hipertexto etc. (Chartier, 1998; Schneider, 1990), e vão configurando novos modos e campos de ação, de indagação, de investigação. De fato, são muitos os trabalhos que levantam questões importantes sobre a autoria, problematizam suas diferentes formas ao longo da história, a responsabilidade sobre o escrito, a propriedade do produto e da obra, as condições de existência do autor, a construção da autoria na escola (Foucault, 1992; Barthes, 1988; Schneider, 1990; Chartier, 1998; Granger, 1974; Orlandi, 1996; Possenti, 2002). Entre esses, o trabalho de Frade (2000) discute de modo interessante como a autoria em revistas da área da educação é construída na relação entre editores e escritores dos textos a serem publicados.

Inspiradas nesses trabalhos, buscamos discutir em nossas análises alguns aspectos da autoria, a qual se constitui numa trama complexa em que se inter-relacionam autor, profissão, gêneros de texto, imagens de leitor, esferas de conhecimento, temas, formas de divulgação... Sem a pretensão de considerarmos todos os meandros dessa trama, queremos ressaltar os lugares de onde falam e os modos de falar dos autores dos textos destinados a professores.

\section{Quem fala, o quê, de onde...}

Numa primeira aproximação das revistas para análise e considerando as características do suporte já apontadas - organização, ficha técnica, objetivos etc. -, deparamo-nos com alguns indicadores que marcam algumas distinções claras entre as revistas: na NE, revista produzida por jornalistas para professores e educadores, tendo como objetivo principal a informação, encontramos diferentes formas de registrar a autoria: o nome completo do autor, apenas as iniciais dos nomes dos autores e até mesmo textos sem indicação de autores jornalistas? Repórteres? Na PP, revista produzida por acadêmicos para 
Duas revistas, três artigos, múltiplas vozes...

professores e educadores, tendo como objetivo distinguir-se no mercado, a autoria é sempre referida, explicitada e qualificada no próprio texto, assumida por docentes de vários níveis de ensino, aparecendo registrada também no índice.

De lugares específicos, portanto, os autores - repórteres, educadores - produzem seus textos. Cada um do seu "mirante", marcado por posições sociais, objetivos, pressupostos teóricos, mais ou menos explícitos, constrói fatos, dados, agencia vozes e escreve seus textos, os quais adquirem sentidos diversos na medida em que integram o conjunto de textos de cada número das revistas.

Alguns críticos têm apontado que a imprensa, especificamente a que trabalha com a divulgação científica, escolhe e constrói o que vem a ser a cada dia, a cada semana ou a cada mês (dependendo da periodicidade das publicaçôes) o fato a ser noticiado (Guimarães, 2001). Podemos concordar que o mesmo ocorre com a parcela da imprensa que trata da área da educação.

Observamos que, em um intervalo muito curto de tempo, as revistas em questão tematizam a violência, destacando-a como matéria de capa, apresentando artigos e reportagens sobre o tema. Como já apontamos anteriormente, no ano de 1999 , a PP publica, no número de julho/agosto, o artigo "Escola e comunidade: resistência à violência", e a reportagem "A humanização do ensino no combate à violência". No mês de setembro, a NE publica a reportagem "O desarme da violência".

Essas publicações acontecem logo após um fato amplamente divulgado pela mídia no âmbito internacional, e que deu origem, posteriormente, ao documentário Tiros em Columbine, de Michael Moore. Esse fato é mencionado por repórteres de ambas as revistas, tornando explícita a intertextualidade 4 que marca o trabalho de autoria, mas aparece com estatutos diferenciados no texto de cada um a partir do modo como são apresentados: como um recurso de problematização inicial na reportagem da PP; ou como mais um fato, entre vários, relacionado ao tema, na NE.

\section{Os textos em foco}

Tendo em conta os limites deste trabalho, vamos concentrar nossas análises dos artigos em três núcleos principais: os modos como 
os autores apresentam o problema, os argumentos principais que eles desenvolvem e as formas de ação e/ou proposição por eles apontadas. Isso implica, também de nossa parte, determinadas escolhas, posições e pontos de vista. ${ }^{5}$

Tomemos em primeira instância o artigo "Escola e comunidade: resistência à violência", publicado na PP de julho/agosto/1999. A autora é identificada e qualificada na revista como professora e graduada em história e mestre em educação. Vejamos como ela inicia seu texto:

Nesse ensaio queremos refletir sobre a necessidade de abrirmos, junto à sociedade, o debate da violência nas escolas. A comunidade escolar vive hoje o drama da barbárie. (...)

Grande parte das escolas públicas encontra-se em regiōes de "risco", provocado, seja pelo tráfico de drogas, seja pelo alto índice de desemprego; ambos são sintomas de uma sociedade centrada na desigualdade, injusta e de um Estado-governo irresponsável com seu dever de garantir o bemestar social (...).

Assim posto, estamos interessados em levar o debate para dentro dos lares, para as ruas. Acreditamos ser o momento de criarmos um movimento que junto à sociedade como um todo, à comunidade em que a escola está localizada, à classe média e às autoridades do poder público, promova espaços que provoquem a reflexão e a ação sobre o drama da violência que atinge os grandes centros urbanos (...).

Importa estimularmos o debate e iniciarmos discussões visando aumentar a consciência da população de um problema que envolve todos nós; portanto, todos devemos nos unir na busca de projetos e posturas propositivas, longe do velho hábito da denúncia, da acusação e da culpabilização.

Identificada como integrando o quadro docente da academia, a autora fala da posição social de docente na universidade - faz uso do pronome na primeira pessoa do plural - e convida os leitores - professores - à reflexão, a partir da afirmação de um drama: o drama da barbárie na comunidade escolar, inserido no drama da violência nas grandes cidades. A autora não só convida à reflexão, mas afirma reiterada e enfaticamente a necessidade de se abrir o debate, iniciar as discussões, conscientizar a comunidade e criar um movimento, colocando-se mesmo na vanguarda desse movimento. Ao longo do texto, podemos destacar algumas marcas dessa reiteração e dessa ênfase: 
Duas revistas, três artigos, múltiplas vozes...

Queremos refletir... Acreditamos ser o momento de criarmos um movimento... Estamos convencidos... Estamos convictos... É preciso insistir...

$\mathrm{Na}$ construção de sua argumentação sobre o assunto, a professora faz referência a autores de diversas posições teóricas. Michel Foucault, J.-P. Sartre, Antonio Nóvoa, Milton Santos, Célia Linhares, entre outros autores, têm palavras citadas. A autora refere-se também a matérias publicadas pela mídia - JB, Folha de S. Paulo, Veja, Cláudia, Exame. Neste sentido, podemos dizer que ela agencia tanto vo$z e s^{6}$ de teóricos e especialistas quanto vozes na mídia. $\mathrm{Na}$ composição do texto, ela afirma como núcleo da argumentação um conjunto de conceitos e valores, utilizando como um dos recursos de linguagem o estabelecimento de um vínculo com o leitor, a partir de um pressuposto supostamente partilhado:

Ora, sabemos que o prazer, a satisfação, resultam na busca de identidade (...).

Identidade, subjetividade e auto-estima são conceitos que compõem a luta pela autonomia de uma escola com projetos que atendam à demanda de sua comunidade (...).

Como podemos falar de identidade, subjetividade, autonomia do aluno se a escola não está interessada em desenvolver, no aluno, a capacidade de escolha e de participação nas decisões?

Identidade, subjetividade, autonomia e auto-estima são conceitos que habitam nossa proposta de uma pedagogia propositiva (...).

Como vai ficando evidente no texto, a proposta apresentada ancora-se fortemente numa posição que proclama a ação individual e o conhecimento de si como base para a participação coletiva. E com base nesse conjunto de conceitos, anunciados mas não necessariamente discutidos no texto, a autora propōe:

Para enfrentar a violência das estruturas e práticas sociais injustas (...), a escola tem que usar da inteligência, da imaginação e do compromisso.

Resta às escolas correrem atrás de parceiros (...).

Nossa proposta é estabelecer parcerias com pessoas e instituições que estejam interessadas em colaborar com a escola no enfrentamento da violência, entre os jovens, nas escolas e/ou fora delas.

Tudo será possível se a escola buscar, fora de seus limites institucionais, parcerias para, juntos, estarem desenvolvendo projetos afins. 
Segue-se a esse artigo de natureza teórico-reflexiva, no mesmo número da revista PP, uma reportagem intitulada "A humanização do ensino no combate à violência", em que a repórter, também identificada como autora do texto, inicia fazendo referência ao episódio de Columbine, buscando relacioná-lo à situação no Brasil:

Dia 20 de abril de 1999 dois adolescentes de classe média promoveram cinco horas de terror em um colégio de Ensino Médio nas proximidades de Denver, no estado americano de Colorado (...).

No Brasil, este ano também tem sido particularmente muito infeliz para o ensino, ou, melhor dizendo, para aqueles que ainda esperam que boa parte dos nossos problemas sejam solucionados através da educação.

Nove bombas em BH... Assassinato do índio patachó (...).

Os índices brasileiros são muito superiores não só aos países desenvolvidos como de outros em semelhante processo de desenvolvimento (...).

Após essa introdução à problemática, a reportagem apresenta a ampla proposta de um renomado colégio particular em São Paulo no combate à violência. A repórter relata diferentes experiências vividas por crianças e adolescentes dessa escola em um projeto desenvolvido desde a pré-escola e as séries iniciais até o ensino médio, que incentiva o contato dos alunos com outros grupos de crianças e escolas menos favorecidas, a começar do reconhecimento do bairro em que o colégio está inserido, chegando a envolver outras regiōes do país, como, por exemplo, o Vale do Jequitinhonha. A repórter afirma que os alunos passam por um processo de inserção social colocando a "mão na massa”. A "inserção social” e a "mão na massa” significam, então, as condições efetivas de contato e as ações a serem realizadas em comunidades carentes, que o colégio propicia aos seus alunos de uma classe privilegiada.

Chamamos atenção para algumas marcas lingüísticas que configuram o lugar da autora da reportagem: como narradora, ela organiza os fatos, utilizando verbos no modo impessoal (como deve-se constatar) e referindo-se aos personagens - alunos e equipe do colégio como eles, em um discurso indireto livre. Podemos dizer que a repórter constrói a narrativa "de fora" do texto e da experiência vivida por aqueles que protagoniza(ra) $\mathrm{m}$ os fatos e as ações. A proposta do artigo, assim, confunde-se com a proposta do colégio, que visa: 
Duas revistas, três artigos, múltiplas vozes...

não só à eliminação de preconceitos, mas o compromisso com ações que preservem o ambiente para melhorar a qualidade da vida de todos e à ação missionária com pessoas de todas as fés religiosas que se colocam a serviço dos seus semelhantes. Não visa só à partilha e à redistribuição de recursos, mas sobretudo à transformação de corações e mentes humanas para iniciar hoje a construção de um novo amanhã.

O conjunto desses dois textos na PP mostra, portanto, uma composição em que docente/especialista da academia e repórter falam, como autores, sobre um mesmo tema. Podem-se notar distinções bastante específicas nos modos de apresentação e construção dos textos, e aqui se explicitam as esferas de atuação e os gêneros de discurso a elas relacionados: convite à reflexão e ao debate, e a reiterada proclamação da necessidade de diálogo, no texto de caráter acadêmico; informação e relato da experiência de outros, no texto de caráter jornalístico.

Uma análise comparativa desses dois textos com a reportagem publicada em setembro, na NE, torna-se aqui bastante oportuna e interessante. Em "O desarme da violência”, o autor do texto, editor especial convidado pela revista, mostra na reportagem 13 exemplos de desarme da violência pela criação de projetos e programas dentro das escolas, no país. O repórter viaja pelos estados, entra nas escolas e conversa com professores, em seis capitais. Mostra não só os modos de convivência com a violência, mas informa sobre e mostra as possibilidades do seu desmonte pela própria comunidade. Como ele introduz ou apresenta a problemática?

O carro avança com dificuldade pelo labirinto tortuoso e esburacado da favela de Parada de Lucas, no subúrbio do Rio de Janeiro. A cada cinqüenta metros, o motorista repete a mesma pergunta: "Onde fica o CIEP Mestre Cartola?” A pergunta é útil e inútil ao mesmo tempo. Ele sabe exatamente aonde quer chegar. A repetição serve para avisar os "soldados" do tráfico de drogas de que aquele carro desconhecido se dirige à escola. Funciona como um salvo-conduto nesse território explosivo e miserável, onde cabras passeiam entre poças de lama, procurando qualquer coisa para comer. Estamos em terreno dominado pela quadrilha chamada de Terceiro Comando; Vigário Geral, mais adiante, pertence ao Comando Vermelho. Entre as duas favelas fica a escola. Poderia ser mais um território marcado pela violência. Mas não é, e vale a pena investigar por quê.

O repórter cria, pela narrativa, uma cenografia, e descreve as açôes de dentro da cena. Ele é o repórter, ator, narrador, autor, que 
convida os leitores à investigação (que ele próprio conduz). $\mathrm{Na}$ construção da reportagem, ele dá destaque aos acontecimentos no Brasil. Aponta as contradições, os antagonismos, ressaltando as ações concretas que têm sido levadas a efeito e os aspectos positivos dessas açóes:

À noite, a violência é de assustar. (...) Ironicamente foi a "Chacina de Vigário Geral”, ocorrida no dia 18 de agosto de 1993, quando deixou saldo de 21 mortos com idades entre 16 e 61 anos, que serviu para unir as duas favelas.

Nunca se falou tanto de violências nas escolas neste ano. Inclusive - e isso é uma boa notícia - dentro das salas de aula.

Abrir a escola para a participação da comunidade dá certo, mas não é fácil. Novos casos de violência, desta vez com nossos alunos, levaram mídia e opinião pública a exigir soluções de curto prazo.

Por decisão das 40 pessoas que compõem o Conselho da Escola, a quadra de esportes continuou aberta para a comunidade.

O pátio da escola se transformou na praça pública que o bairro deveria ter e não tem.

Música, teatro, esporte, atividades extracurriculares, conversas e normas claras (...).

Em vez de se falar em violência, é melhor conversar sobre a paz.

Vemos assim que, ao passo que o artigo da pp fala da necessidade de se abrir o debate e de mobilizar a comunidade - lares, ruas, escolas -, a reportagem da NE mostra efetivamente o que já está sendo feito nas escolas públicas do país, apontando, inclusive, para formas de envolvimento intenso e imediato da comunidade. A descrição e as fotos de diversos projetos entremeiam a reportagem em boxes que ocupam três quartos da página. Cada um desses projetos ou iniciativas ganha um subtítulo: Trabalho de mestre na periferia (CIEP Mestre Cartola, RJ); Revolução pacífica em dois anos (EEPG Prof. Renato Arruda, SP); A violência entre duas escolas vira ficção (EM Maria Mazarello, BH); Tiros lá fora, som ambiente dentro da escola (EM Mauro Faccio Gonçalves, SP); Vinte minutos diários de arte-educação (Escola Classe Varjão, DF); A paz em verde e rosa (CIEP Nação Mangueira, RJ); A escola que ficou maluquinha por limpeza (EEPG Padre Palmeira, Salvador, BA); Eles se decidiram pela paz (Escola Classe 18, Brasília, DF); Reação orquestrada contra a violência (CAIC Maria Felício Lopes, Fortaleza, CE). Cada uma das escolas é identificada, seguindo-se o endereço e o telefone para contato. 
Duas revistas, três artigos, múltiplas vozes...

Nesse trabalho, o repórter também agencia muitas vozes: da secretária de Educação; de diretores das escolas, coordenadores pedagógicos, supervisores de ensino, professores na escola, alunos, pais, especialistas e professores na academia... Utilizando muitas vezes o discurso direto, ou seja, colocando as falas entre aspas, ele constrói o texto dando a palavra aos entrevistados, que representam diversas posições dentro e fora da escola.

Podemos constatar que o texto traz efetivamente marcas comumente apontadas da linguagem jornalística - a colocação entre aspas das falas e dos depoimentos, seguidos de verbos como "afirma", "diz", "conta". Isso desloca do repórter a responsabilidade direta sobre esses dizeres, ao mesmo tempo em que esses mesmos dizeres se tornam por ele "apropriados" (tornam-se "próprios" do autor/repórter, configurando um estilo no gênero jornalístico) na construção da autoria. ${ }^{7}$ Nessa reportagem, então, as propostas (con)fundem-se com o próprio relato do autor, na medida em que os argumentos do repórter se ancoram em ações e depoimentos das pessoas que participam e legitimam experiências coletivas no âmbito da instituição escolar. Ao final da reportagem em que traz a público projetos que "deram certo", o repórter conclui:

As iniciativas aqui contempladas, e centenas de outras ainda anônimas, apontam para a mesma saída: trazer a criança para passar a maior parte do seu tempo dentro da escola, reforçando em todas as oportunidades e espaços a idéia de cidadania - o aluno pertence a uma comunidade escolar, que se mistura à comunidade de seu bairro e ao espaço familiar. Apoiado nesse tripé ele aprenderá, em liçôes práticas, o que significa cidadania. Se a violência do dia-a-dia invadiu a escola, não há dúvida de que a paz na sociedade só virá por meio da educação de seus cidadãos. $\mathrm{E}$, nesta guerra, um bom professor, ensinando como se convive em paz com a diferença, vale mais que um batalhão de policiais bem armados.

Admitindo a possibilidade de existirem milhares do outros esforços que ainda não se tornaram públicos, que permanecem anônimos, o repórter aponta ainda para medidas que podem viabilizar-se e incorporar-se nas políticas educacionais: maior tempo na escola para as crianças; articulaçôes família, escola, bairro; a escola como lugar de construção da cidadania; a importância da formação de professores; e uma certa utopia: a paz virá por meio da educação... 
... para quem?

Enfatizando o caráter sempre partilhado de qualquer enunciação, Bakhtin $(1981,1992)$ nos diz que uma palavra sempre se dirige a alguém, é sempre uma ponte entre interlocutores. Como podemos conceber e interpretar essa palavra - enunciada pelos escritores/ autores dos textos nas revistas - orientada para os professores? E como esses diferentes textos, essas palavras escritas, afetam os interlocutores, os professores leitores? No início deste trabalho, especulávamos sobre o que os professores buscavam na leitura das revistas, sobre as suas formas e condições de leitura, sobre suas necessidades... Não temos, ainda, elementos para responder a essas indagaçôes. Um outro estudo seria necessário com o objetivo de escutar as réplicas ${ }^{8}$ dos professores a esses artigos.

No entanto, o que podemos dizer, neste momento, é a partir de possíveis análises das imagens de professor/leitor que se esboçam nos próprios textos dos autores, em função mesmo da posição que esses últimos ocupam na interlocução, do trabalho que realizam e dos modos como agenciam as vozes dos outros. Retomemos, então, alguns pontos:

As revistas, orientadas, em princípio, para um mesmo público professores da rede de ensino, prioritariamente da educação básica -, têm formulado objetivos bastante específicos, apresentando e fazendo circular, de diferentes maneiras, uma série de informações e de conhecimentos. Esse "mesmo" público, então, tende a se diversificar, não só com relação aos objetivos das próprias revistas, mas também em função dos objetivos dos leitores - necessidade de informação ou busca de formação.

Mas será que os objetivos - das revistas e dos leitores - mantêm-se assim tão distintamente? A trama é complexa. Vimos que na $\mathrm{NE}$ a reportagem realizada por jornalistas é a atividade principal que estrutura a revista. $\mathrm{Na}$ PP, o artigo escrito por especialistas ou acadêmicos tem um lugar central, sendo que a reportagem tem um caráter complementar. Os modos diferenciados de produção de texto - artigo, reportagem - estão intimamente ligados às esferas específicas de atividade dos autores (professores, repórteres, editores), o que nos leva a pontuar os fazeres e os dizeres específicos do trabalho de reportagem como fazer jornalístico e do trabalho de pesquisa (teórica ou 
Duas revistas, três artigos, múltiplas vozes...

empírica) como produção acadêmica. Ambos os fazeres e dizeres implicam trama de vozes, referência ao outro, trabalho no intertexto. Vimos também que as revistas, de caráter jornalístico e/ou pedagógico, apresentam-se como meios/modos de veicular informaçóes e/ou incitar o debate, sendo que os textos acabam por configurar o que se pode caracterizar como um gênero híbrido de discurso, na medida em que, transitando nas interseções da educação e do jornalismo, tramam vozes de diferentes lugares, trazendo marcas de discursos acadêmico, pedagógico e jornalístico.

Neste sentido, as matérias publicadas nas revistas não se restringem a assuntos didático-pedagógicos. A violência, por exemplo, na medida em que afeta a escola, torna-se objeto de apresentação e tema de discussão nas revistas, inserindo-se, oportunamente, no âmbito dos acontecimentos mais amplamente divulgados na mídia. Os modos de apresentação e problematização dessa temática variam.

Com relação aos textos analisados, pudemos perceber que, ao passo que a composição da reportagem na NE explicita as vozes e posições sociais de onde falam os protagonistas, a reportagem na PP traz essas vozes implícitas, ou seja, não há referência às pessoas que participaram das entrevistas ou deram depoimentos ou informações. Também o artigo analisado da PP agencia vozes, faz referência, coloca entre aspas os dizeres dos outros. Mas de quem? Geralmente de outros autores, teóricos e especialistas, tendo como objetivo refletir, discutir, apresentar pesquisas, investigar. Investigar, no entanto, também faz parte da atividade jornalística: (...) vale a pena investigar por quê. E o que parece diferenciá-las, numa esfera e na outra, são as funções, as posiçóes e os objetivos de quem realiza uma atividade específica.

Os modos de investigar e agenciar as vozes acabam sendo marcantes e distintivos no caso da produção desses textos sobre violência para os professores.

Vimos que a professora, docente na academia, que escreve na PP (n)os convoca à reflexão, argumentando sobre a necessidade de debate e conscientização da comunidade, e propondo o estabelecimento de parcerias entre escolas e outras instituições, governamentais e nãogovernamentais, como uma saída para solucionar o problema da violência. Sua investigação tem um caráter predominantemente bibliográfico e, com relação à escola, ela anuncia: 
(...) o dia em que as escolas públicas deixarem de ser o lugar do descaso, da pobreza, da negação, da discriminação, da falta (de professor, material, espaço físico) (...) então ela, escola, estará preparada para resistir à violência e ao estado de barbárie que estamos vivendo.

Queremos ver o dia em que a escola promoverá espaços e uma cultura da não-violência (...).

A repórter que escreve na mesma revista apresenta, então, como uma estratégia contra a violência, um projeto de uma escola particular que visa à humanização do ensino. O relato da experiência ilustra uma possibilidade concreta de ação, a partir de um caso e de um segmento bastante específico da sociedade. Nesses dois textos, o professor - seu ofício, sua fala - não é destacado; seu papel é subsumido pelo da escola, e não ressaltado no interior dela.

$\mathrm{O}$ editor/repórter que escreve na NE informa sobre e dá a conhecer uma diversidade de projetos, todos desenvolvidos em escolas públicas situadas em territórios marcados pela violência. As escolas poderiam ser também espaços marcados pela violência, mas não são. E nas suas investigações, ele mostra diferentes formas de participação e envolvimento da comunidade em projetos educativos, artísticos, esportivos, culturais, que fazem da escola um lugar possível de convivência e construção da cidadania. Ele fala de e com professores, para professores. E assim responde, de certo modo, aos anseios explicitados pela autora do artigo na PP.

Os modos como falam (ou não) do professor, do seu ofício, da sua função social; os modos como integram no seu texto as vozes desse profissional da educação acabam por dizer também das imagens desse interlocutor, que são constitutivas do trabalho de autoria de textos orientados para os professores. Para nós, que trabalhamos na academia, com professores e com a formação de professores, fica a instigante tarefa de pensar como nos situamos, como leitores e escritores de textos para professores, nessa trama intertextual.

Recebido em agosto de 2003 e aprovado em abril de 2004.

\section{Notas}

1. Gentil, Duas revistas, múltiplas vozes, um mesmo tema, XII Encontro Nacional da Associação Brasileira de Psicologia Social, Porto Alegre, RS, 2003. 
Duas revistas, três artigos, múltiplas vozes...

2. Essa organização foi marcada durante anos, tendo mudado no decorrer de 2003.

3. NE, 2000, 2001, 2002, 2003.

4. Cf. Foucault, 1967, e Bakhtin, 1992.

5. Neste texto, estamos apresentando um estudo e assumindo uma posição de dentro da academia.

6. Cf. Bakhtin, 2002.

7. Cf. Bakhtin, 1992.

8. Cf. Bakhtin, 1981, 1992.

Referências bibliográficas

BAKHTIN, M. Marxismo e filosofia da linguagem. São Paulo: Hucitec, 1981.

BAKHTIN, M. Gêneros do discurso. In: BAKHTIN, M. Estética da criação verbal. São Paulo: Martins Fontes, 1992.

BAKHTIN, M. Problemas da poética de Dostoiévski. Rio de Janeiro: Forense Universitária, 2002.

BARTHES, R. A morte do autor. In: BARTHES, R. O rumor da lingua. São Paulo: Brasiliense, 1988.

CHARTIER, R. Figuras do autor. In: ChARTIER, R. A ordem dos livros. Brasília, DF: UNB, 1998.

CHARTiER, R. (Org.). Práticas da leitura. São Paulo: Estação Liberdade, 2001.

FOUCAULT, M. A arqueologia do saber. Rio de Janeiro: Forense, 1967.

FOUCAULT, M. O que é um autor? S.l.: Passagens, 1992.

FRADE, I.C.A.S. Imprensa pedagógica: um estudo de três revistas mineiras destinadas a professores. 2000. Tese (Doutorado) - Faculdade de Educação, Universidade Federal de Minas Gerais, Belo Horizonte.

GRANGER, G.-G. Conteúdo, forma e prática. In: Granger, G.-G. Filosofia do estilo. São Paulo: Perspectiva; Edusp, 1974. 
Maingueneau, D. O etos. In: Maingueneau, D. O contexto da obra literária: enunciação, escritor, sociedade. São Paulo: Martins Fontes, 1995.

MAINGUENEAU, D. El ethos y la voz de lo escrito. In: Versión 6. México: UAM, 1996.

MAINGUENEAU, D. Novas tendências em análise do discurso. Campinas: Pontes; UNICAMP, 1997.

Maingueneau, D. Análise de textos de comunicação. São Paulo: Cortez, 2001.

Maingueneau, D. O ethos. In: Maingueneau, D. Análise de textos de comunicação. São Paulo: Cortez, 2001.

ORLANDI, E.P. Nem escritor, nem sujeito: apenas autor. In: ORLANDI, E.P. Discurso e leitura. São Paulo: Cortez; Campinas: UnICAMP, 1993.

ORLANDI, E.P. Autoria e interpretação. In: ORLANDI, E.P. Interpretação: autoria, leitura efeitos do trabalho simbólico. Petrópolis: Vozes, 1996.

POSSENTI, S. Enunciação, autoria e estilo. Revista da FAEEBA, Salvador, v. 10, n. 15, jan./jun. 2001.

POSSENTI, S. Indícios de autoria. Perspectiva, Florianópolis, v. 20, n. 1, jan./jun. 2002.

SCHNEIDER, M. Ladrões de palavras. Campinas: UnICAMP, 1990.

SILVA, L.L.M. Revista Leitura: teoria e prática e o professor; um leitor em formação. In: Marinho, M.; Silva, C.S.R. (Org.). Leituras do professor. Campinas: Mercado de Letras; ALB, 1998.

VIEIRA, M.L. Construtivismo: a prática de uma metáfora; forma/conteúdo do "construtivismo" em Nova Escola. 1995. Dissertação (Mestrado) Faculdade de Educação, Universidade Federal de Minas Gerais, Belo Horizonte. 